\title{
INTENTIONAL LIMITED RESECTION FOR SELECTED PATIENTS WITH T1 NO MO NON-SMALL-CELL LUNG CANCER: A SINGLE-INSTITUTION STUDY
}

Ken Kodama, MD

Osamu Doi, MD

Masahiko Higashiyama, MD

Hideoki Yokouchi, MD
Objectives: To comparatively evaluate lobectomy and limited resection for T1 N0 M0 non-small-cell lung cancer, we reviewed case series with concurrent nonrandomized controls. Methods: Limited resection with curative intent was performed for 63 patients with T1 NO M0 non-small-cell lung cancer over a 10-year period. These 63 patients included 46 patients who underwent a segmentectomy as an intentional limited resection. These patients had good pulmonary function and could tolerate a lobectomy in the management of their disease. The other 17 patients underwent wedge resection or segmentectomy as a compromised limited resection because they had poor pulmonary reserve or other limiting factors and could withstand a thoracotomy but could not tolerate a lobectomy in the management of their disease. Results: The 5-year survival was $93 \%$ in the intentional resection group. The survival curve for this group was not different from that for 77 patients who underwent the standard operation (lobectomy plus complete mediastinal lymph node dissection) for T1 N0 M0 non-small-cell lung cancer during the same period. The frequency of local/regional recurrence in the intentional resection group was $8.7 \%$ (4/46); the recurrence in three patients was situated in the mediastinum. According to multivariate analysis, limited resection was not associated with poor survival. Conclusion: Segmentectomy with regional lymph node dissection, including the mediastinum, should be considered as an acceptable alternative treatment for selected patients with T1 N0 M0 disease. (J Thorac Cardiovasc Surg 1997;114:347-53)
$\mathrm{R}$ ecently, a prospective randomized trial disclosed an unfavorable result after limited resection for the management of patients with $\mathrm{T} 1 \mathrm{~N} 0$ non-smallcell lung cancer (NSCLC) as compared with lobectomy because of the higher frequency of local/ regional recurrence with the limited operation. ${ }^{1}$ On the other hand, a slightly better survival for the segmentectomy group, as compared with the lobectomy group, was reported in a retrospective nonran-

From the Department of Thoracic Surgery, Osaka Medical Center for Cancer \& Cardiovascular Diseases (The Center for Adult Diseases, Osaka), 1-3-3 Nakamichi, Higashinari-ku, Osaka 537, Japan.

Received for publication Sept. 23, 1996; revisions requested Nov. 11, 1996; revisions received April 15, 1997; accepted for publication April 16, 1997.

Address for reprints: Ken Kodama, MD, Department of Thoracic Surgery, Osaka Medical Center for Cancer \& Cardiovascular Diseases (The Center for Adult Diseases, Osaka), 1-3-3 Nakamichi, Higashinari-ku, Osaka 537, Japan.

Copyright (1) 1997 by Mosby-Year Book, Inc.

$0022-5223 / 97 \$ 5.00+0 \quad \mathbf{1 2 / 1 / 8 2 6 7 6}$ domized study. ${ }^{2}$ Moreover, the treatment of patients having bilateral synchronous and metachronous primary tumors with standard pulmonary resection for one tumor and lesser resection for the contralateral tumor has certainly provided a curative procedure for many individuals. ${ }^{3}$

The following report describes our retrospective review of patients with T1 N0 M0 NSCLC treated at Osaka Medical Center for Cancer \& Cardiovascular Diseases. In the past decade the surgeons at this hospital have performed segmentectomy for selected patients whose lung function is adequate to tolerate a standard lobectomy.

\section{Patients and methods}

Patient population. Between January 1985 and September 1996, 913 patients with NSCLC (squamous cell carcinoma, adenocarcinoma, or large-cell carcinoma) underwent resections at Osaka Medical Center for Cancer \& Cardiovascular Diseases. Among 181 of these patients who were pathologically classified as having T1 N0 M0 carcinoma located in the peripheral lung parenchyma, 63 patients $(34.8 \%)$ underwent limited resection and 77 
patients $(42.5 \%)$ had a standard lobectomy procedure (lobectomy plus complete mediastinal lymph node dissection). Forty-six of the 63 patients $(25.4 \%)$ who underwent a limited operation had been considered suitable candidates for a standard lobectomy procedure with mediastinal lymph node dissection. This determination was made after assessing pulmonary function with spirometry and examination of arterial blood gases. These patients were classified as the intentional resection group. We started doing this procedure in 1985 . The additional 17 patients (9.4\%) who underwent limited operations were considered unsuitable candidates for lobectomy because of poor pulmonary reserve, combined diseases such as coronary artery disease, or older age, and were classified as the compromised resection group. Forty-one patients (22.7\%) who underwent lobectomy without mediastinal lymph node dissection were excluded from the present study.

After obtaining informed consent from the patients regarding the operative methods, we decided what type of resection to perform after reviewing the preoperative and intraoperative findings (tumor shape, location, size, and lymph node status). In deciding whether to apply an intentional limited resection, we also carefully considered the predicted residual lobar volume. As a rule, we performed a limited resection in patients with a tumor less than $2 \mathrm{~cm}$ in diameter with a well-defined margin in the peripheral lung parenchyma. Even though smaller than 2 $\mathrm{cm}$ in diameter, tumors showing strong spicula in the preoperative computed tomographic scans were considered contraindications for limited resection.

Surgical procedures. Segmentectomy or bisubsegmentectomy was applied in all patients in the intentional resection group and in 14 of the 17 patients in the compromised resection group. Three patients in the latter group underwent wedge resection. General anesthesia with the use of a double-lumen endotracheal tube was standard at this time. A lateral muscle-sparing thoracotomy and laser segmentectomy performed with a neodymium:yttrium-aluminum-garnet (Nd:YAG) laser was used in most cases. We $\mathrm{H}^{4}$ have previously described the precise details of how this laser is used. In brief, before a decision regarding the amount of lung tissue to be removed was made, bronchial node biopsies were performed and the specimens submitted for frozen section examination. After hilar management, nonanatomic resection of the lung parenchyma was carried out with a noncontact laser-focusing handpiece to maintain a constant safety margin of about $3 \mathrm{~cm}$ from the tumor edge. When the tumor extended across the intersegmental lung parenchyma, two subsegmental bronchi were resected to maintain the constant safety margin. The small vessels and bronchioles in the laser-irradiated field were carefully ligated.

Statistical analysis. The survival curves and the patterns of recurrences of these three groups were compared. The survival curves were calculated by the Kaplan-Meier method, and the statistical comparisons among the curves were made by means of the log-rank test. We defined local/regional recurrence as the development of an additional carcinoma in the mediastinum or the resected margin. Unpaired two-tailed $t$ tests were used for the comparison of mean values. The $\chi^{2}$ test was used to compare observed percentages. Variables related to survival in patients with standard lobectomy or intentional limited resection were analyzed by Cox's proportional hazards regression model with SAS software (SAS Institute, Inc., Cary, N.C.). Values of $p$ less than 0.05 were considered to be statistically significant.

\section{Results}

One hundred forty patients aged 35 to 87 years were studied. As shown in Table I, 77 standard operations were performed, 46 intentional limited operations and 17 compromised limited operations. The average age in the compromised resection group was significantly higher than that in either of the other two groups $(p<0.0001)$. The median follow-up period was 83 months for the standard lobectomy group, 30 months for the intentional resection group, and 61 months for the compromised resection group. The high percentage of men was characteristic of patients having compromised limited resection. The difference in the distribution of histologic types among these three groups was not statistically significant. The average diameter for pulmonary nodules was $22.9 \mathrm{~mm}$ in the standard resection group, $16.7 \mathrm{~mm}$ in the intentional resection group, and $22.4 \mathrm{~mm}$ in the compromised resection group. Overall, tumors in the intentional resection group were smaller than those in the other two groups $(p<0.0001$ and $p<0.001)$. The forced expiratory volume in 1 second of the compromised resection group was significantly worse than that of the other two groups ( $p=0.006$ and $p<0.001$ ). Arterial oxygen tension did not differ significantly among these three groups.

The tumors were primarily located in the upper lobes (41 [65\%]: right, $n=21$; left, $n=20$ ). Twenty-two tumors $(35 \%)$ were located in the lower lobes (right, $n=9$; left, $n=13$ ).

All but three of the patients in the compromised resection group underwent segmentectomy or bisubsegmentectomy. In the intentional resection group, 13 patients underwent hilar and complete mediastinal lymph node dissection, and 28 underwent hilar node dissection with incomplete mediastinal lymph node dissection. An additional five patients did not undergo lymph node dissection because of no detectable lymph node on computed tomography. On the other hand, mediastinal lymph node dissection was not attempted in any of the 17 patients in the compromised resection group.

We initially attempted an intentional limited operation in an additional six patients. However, frozen section and intraoperative histologic diagnostic 


\begin{tabular}{|c|c|c|c|c|}
\hline & \multirow[b]{2}{*}{ Standard lobectomy* } & \multicolumn{3}{|c|}{ Limited operation } \\
\hline & & Intentional & & Compromised \\
\hline No. of patients & 77 & 46 & \multirow{3}{*}{$p<0.0001$} & 17 \\
\hline Age (yr) (range) & $61(39-87)$ & $61(35-77)$ & & $73(58-82)$ \\
\hline $\operatorname{Sex}(M / F)$ & $\begin{array}{l}46 / 31 \\
I\end{array}=0.03$ & $31 / 15$ & & $15 / 2$ \\
\hline Median follow-up (mo) & 83 & 30 & & 61 \\
\hline \multicolumn{5}{|l|}{ Histologic type } \\
\hline Squamous cell & 13 & 8 & & 7 \\
\hline Adenocarcinoma & 61 & 36 & & 10 \\
\hline Large cell & 3 & 2 & & 0 \\
\hline Tumor diameter $(\mathrm{mm})($ mean $\pm \mathrm{SD})$ & $\begin{array}{l}22.9 \pm 5.22 \\
L\end{array}$ & $16.7 \pm 4.97$ & $p<0.001$ & $\begin{array}{l}22.4 \pm 6.61 \\
\end{array}$ \\
\hline $\begin{array}{l}\text { Preop. respiratory function (mean } \pm \mathrm{SD} \text { ) } \\
\mathrm{FEV}_{1}(\mathrm{~L})\end{array}$ & $2.33 \pm 0.69$ & $2.46 \pm 0.57$ & $p<0.001$ & $1.77 \pm 0.57$ \\
\hline $\mathrm{FVC}(\mathrm{L})$ & $2.91 \pm 0.79$ & $\begin{array}{c}3.09 \pm 0.66 \\
\end{array}$ & $p=0.005$ & $2.49 \pm 0.64$ \\
\hline
\end{tabular}

$S D$, Standard deviation; Preop., preoperative; $F E V_{l}$, forced expiratory volume in 1 second; $F V C$, forced vital capacity.

*Lobectomy with mediastinal lymph node dissection.

evaluation confirmed $\mathrm{N} 2$ disease in two of these patients, and they were thus excluded from the present study because their disease had progressed to a different stage. Four of these patients had an insufficient safe margin and were thus included in the standard lobectomy group because we altered the procedure from segmentectomy to lobectomy with mediastinal lymph node dissection.

The overall survival proportion at 5 years calculated by the Kaplan-Meier method (Fig. 1) was $88 \%$ in the standard lobectomy group and $93 \%$ in the intentional resection group. No statistically significant difference between these two groups was detected in the survival curves $(p=0.86)$. However, in the compromised resection group, the 5-year survival was $48 \%$. The survival curve in the compromised resection group was significantly lower than those in the other two groups $(p<0.001$ and $p=$ 0.003 ).

The clinical outcome in each group is presented in Table II. No operation-related deaths occurred. In the standard lobectomy group, three patients (3.9\%) died of lung cancer recurrence. In this group, deaths from other causes included death from other cancers, deaths causes unrelated to cancer, and death from unknown causes. Sixty-six patients $(85.7 \%)$ are alive with no evidence of disease, and two $(2.6 \%)$ are alive with recurrent disease. In the intentional resection group, four patients $(8.7 \%)$ died of lung cancer recurrence. Forty patients $(87.0 \%)$ are alive with no evidence of disease, and two (4.3\%) are alive with recurrent disease. In the compromised resection group, three patients $(17.6 \%)$ died of lung cancer recurrence. Ten patients $(58.8 \%)$ are alive with no evidence of disease, and one $(5.9 \%)$ is alive with recurrent disease. The incidence of lung cancer deaths or recurrences in the compromised resection group was higher $(p=0.05)$ than that in the standard lobectomy group. Although noncancer or other cancer death was more prevalent in the compromised resection group than in the other two groups, the difference was not significant. The causes of death in the two patients with noncancer death were acute myocardial infarction in one and chronic obstructive pulmonary disease in the other. The recurrence rates did not differ significantly $(p=$ 0.49 ) between the standard lobectomy group and the intentional resection group.

The patterns of tumor recurrence are presented in Table III. The frequency of development of local/regional recurrence with or without distant metastasis in the intentional resection group was not higher $(p=0.12)$ than that in the standard lobectomy group. The compromised resection group showed significantly higher frequency $(p=0.02)$ of local/regional recurrence compared with the lobectomy group.

Table IV shows the clinical details for the six 


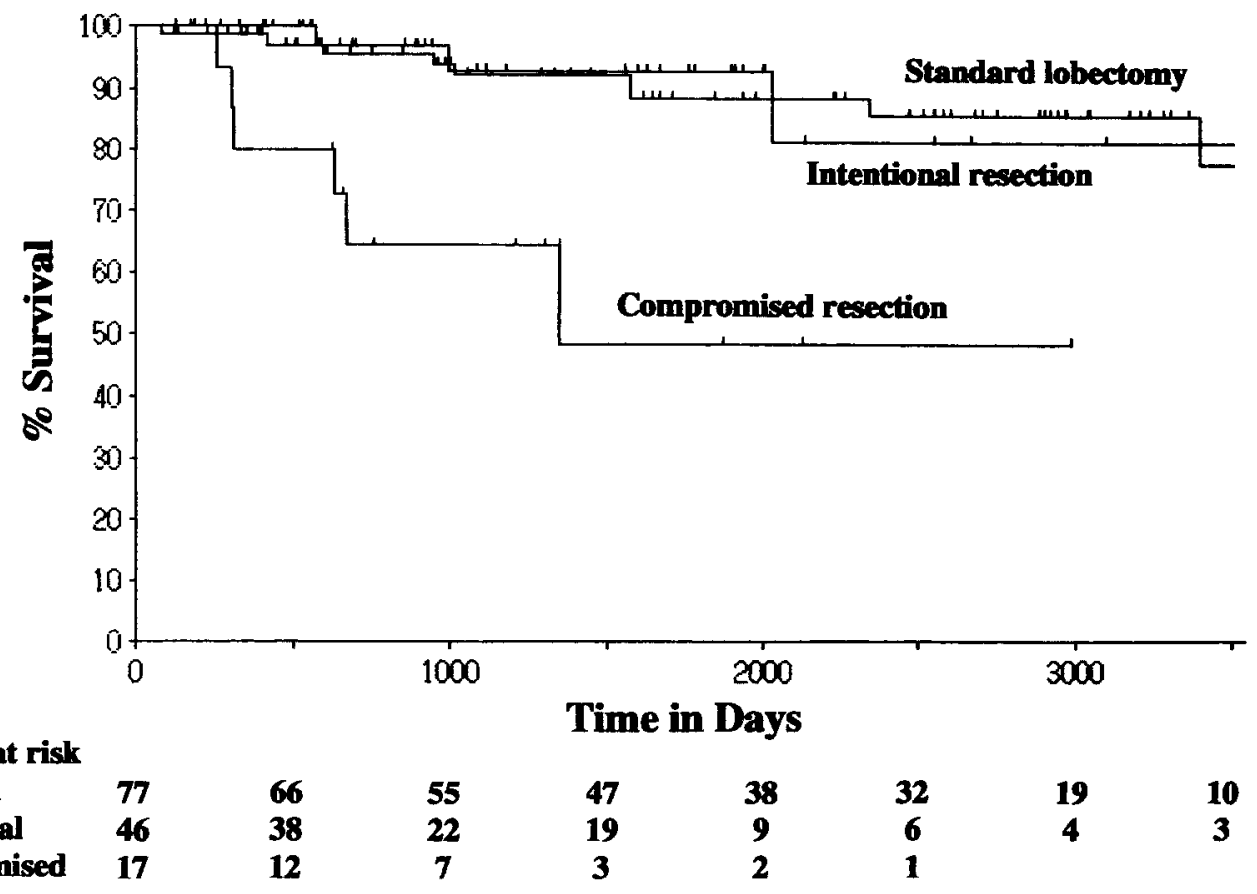

Fig. 1. Comparison of survival curves among the three groups (standard vs intentional: $p=0.86$; standard vs compromised: $p<0.001$; intentional vs compromised: $p=0.003$ ).

Table II. Clinical outcome

\begin{tabular}{|c|c|c|c|c|c|c|}
\hline & & & \multicolumn{4}{|c|}{ Limited resection } \\
\hline & \multicolumn{2}{|c|}{ Standard lobectomy } & \multicolumn{2}{|c|}{ Intentional } & \multicolumn{2}{|c|}{ Compromised } \\
\hline & No. & $\%$ & No. & $\%$ & No. & $\%$ \\
\hline Lung cancer deaths & 3 & $3.9^{*}$ & 4 & 8.7 & 3 & $17.6^{*}$ \\
\hline Other cancer deaths & 1 & 1.3 & 0 & 0 & 1 & 5.9 \\
\hline Noncancer death & 3 & 3.9 & 0 & 0 & 2 & 11.8 \\
\hline Unknown & 2 & 2.6 & 0 & 0 & 0 & 0 \\
\hline \multicolumn{7}{|l|}{ Alive } \\
\hline With recurrence & 2 & $2.6^{*}$ & 2 & 4.3 & 1 & $5.9^{*}$ \\
\hline Without recurrence & 66 & 85.7 & 40 & 87.0 & 10 & 58.8 \\
\hline Total & 77 & 100 & 46 & 100 & 17 & 100 \\
\hline
\end{tabular}

*The incidence of lung cancer death or recurrence in the compromised resection group is statistically higher $(p=0.05)$ than that in the standard lobectomy group.

patients with recurrent disease in the intentional resection group. Four patients had adenocarcinoma and one each had squamous cell carcinoma and large-cell carcinoma. Mediastinal lymph node metastasis or distant metastasis developed in two patients with tumor less than $20 \mathrm{~mm}$ in diameter. Mediastinal recurrence occurred in three patients without complete mediastinal lymph node dissection (patients 1, 4, and 5). The patient with intrapulmonary recurrence at the margin and the patient with lung metastases in a different lobe both underwent successful additional complete resection. They are alive with no evidence of disease. In patient 2, distant metastases were confined to the extrathoracic lymph nodes.

In three patients in the compromised resection group who had local/regional recurrence, the recurrence was in the mediastinum. Of those three patients, one also had an intrapulmonary recurrence at the margin after resection of a $25 \mathrm{~mm}$ squamous cell carcinoma.

By Cox's multivariate analysis, tumor size and age 


\begin{tabular}{|c|c|c|c|c|c|c|}
\hline & & & \multicolumn{4}{|c|}{ Limited resection } \\
\hline & \multicolumn{2}{|c|}{ Standard lobectomy } & \multicolumn{2}{|c|}{ Intentional } & \multicolumn{2}{|c|}{ Compromised } \\
\hline & No. & $\%$ & No. & $\%$ & No. & $\%$ \\
\hline Local/regional & 1 & $1.3^{*}$ & 1 & 2.2 & 2 & $11.8^{*}$ \\
\hline Distant & 4 & 5.2 & 2 & 4.3 & 1 & 5.9 \\
\hline Both & 0 & $0^{*}$ & 3 & 6.5 & 1 & $5.9^{*}$ \\
\hline Total & $5 / 77$ & 6.5 & $6 / 46$ & 13.0 & $4 / 17$ & 23.6 \\
\hline
\end{tabular}

*The frequency of development of local/regional recurrence with or without distant metastasis in the compromised resection group was statistically higher $(p=0.02)$ than that in the standard lobectomy group.

Table IV. Clinical details of six patients with recurrent diseases after intentional limited resection for T1 NO MO NSCLC

\begin{tabular}{cccclcccc}
\hline $\begin{array}{c}\text { Patient } \\
\text { No. }\end{array}$ & Age/sex & His & $\begin{array}{c}\text { Size } \\
(\mathrm{mm})\end{array}$ & Location & LyD & Laser & Recurrence site & Results \\
\hline 1 & $51 / \mathrm{M}$ & Sq & 17 & R-S2 & 1 & - & Mdst and lung & $119 \mathrm{mo}$, dead \\
2 & 69/F & Ad & 18 & L-S8 & 2 & - & Distant LN & $66 \mathrm{mo}$, dead \\
3 & $57 / \mathrm{M}$ & Ad & 25 & R-S2-3 & 2 & - & Margin* & $83 \mathrm{mo}$ alive \\
4 & $75 / \mathrm{M}$ & La & 25 & L-S3-4 & 0 & + & Mdst and liver & $18 \mathrm{mo}$, dead \\
5 & $77 / \mathrm{M}$ & Ad & 24 & R-S6 & 1 & + & Mdst and liver & $32 \mathrm{mo}$ dead \\
6 & $58 / \mathrm{F}$ & Ad & 20 & R-S2-3 & 2 & + & Lung $\dagger$ & $50 \mathrm{mo}$, alive \\
\hline
\end{tabular}

$H i s$, Histologic type; $S q$, squamous cell carcinoma; $A d$, adenocarcinoma; $L a$, large-cell carcinoma; $R-S$, segments of the right lung; $L-S$, segments of the left lung; $L y D$, lymph node dissection $(0=$ no lymph node dissection; $1=$ hilar lymph node dissection; $2=$ hilar and mediastinal lymph node dissection); $M d s t$, mediastinum; $L N$, lymph node.

*Completion bilobectomy.

$\uparrow$ Right lower lobectomy.

were independent predictors of survival when considered together with sex, surgical procedures (intentional limited resection vs standard lobectomy), and histologic types (Table V).

\section{Discussion}

Lobectomy combined with regional lymph node dissection has long been accepted as the standard treatment for lung cancer. Since Jensik and associates $^{5}$ reported the outcome after segmental resection for lung cancer, the procedure has become an accepted surgical option for patients with compromised pulmonary reserve. ${ }^{6}$ Segmentectomies have also been proposed as the procedure of choice for stage I carcinoma of the lung whenever the tumor location allows for the procedure. ${ }^{2}$

Recent retrospective analyses by Warren and Faber ${ }^{7}$ suggested that lobectomy offered no survival advantage over segmentectomy for patients with tumors $3.0 \mathrm{~cm}$ in diameter or smaller, but that a survival advantage was apparent for patients with tumors larger than $3.0 \mathrm{~cm}$. Warren and Faber $^{7}$ pointed out that patients undergoing segmental pulmonary resections have a 4.6 -fold increased risk of local/regional recurrence within the next 5 years compared with those undergoing lobectomy for stage I carcinomas. However, because the majority of patients with local/regional recurrence died of distant metastases, this did not affect the 5-year survival in the two groups. In the study by Read, Yoder, and Schaeffer, ${ }^{2}$ the proportion surviving was slightly better for the segmentectomy group than for the lobectomy group with T1 N0 M0 disease. Both authors ${ }^{2,7}$ recommend that, in the absence of distant metastases, patients with a local/regional recurrence be treated with additional resection whenever possible, rather than with palliative radiotherapy. In our study, as a result of the careful selection of patients to undergo intentional limited resection, the average maximal tumor diameter in the intentional resection group was significantly smaller than those in the standard lobectomy and compromised resection groups. Each of the patients with local/ regional recurrence and metastases of a different ipsilateral lobe was successfully treated with additional resection and is presently in good condition.

A prospective randomized trial of lesser resections compared with lobectomy for T1 N0 NSCLC 
Table V. Cox's regression analysis of survival in 123 patients with standard lobectomy or intentional limited resection

\begin{tabular}{|c|c|c|c|c|c|}
\hline Variables & No. & $\begin{array}{l}\text { No. of } \\
\text { deaths }\end{array}$ & $\begin{array}{c}\text { Hazard } \\
\text { ratio }\end{array}$ & $95 \% \mathrm{CI}$ & $p$ Value \\
\hline \multicolumn{6}{|l|}{ Tumor size (mm) } \\
\hline$<20$ & 55 & 2 & 6.0 & $3.9-9.3$ & 0.04 \\
\hline$\geq 20$ & 68 & 10 & & & \\
\hline \multicolumn{6}{|l|}{ Age (yr) } \\
\hline$<60$ & 49 & 1 & 9.3 & $5.4-15.9$ & 0.04 \\
\hline$\geq 60$ & 74 & 11 & & & \\
\hline \multicolumn{6}{|l|}{ Sex } \\
\hline Male & 77 & 9 & 0.4 & $0.3-0.5$ & 0.17 \\
\hline Female & 46 & 3 & & & \\
\hline \multicolumn{6}{|l|}{ Procedure } \\
\hline Segmentectomy & 46 & 4 & 0.4 & $0.3-0.6$ & 0.19 \\
\hline Lobectomy & 77 & 8 & & & \\
\hline \multicolumn{6}{|l|}{ Histologic type } \\
\hline Squamous & 21 & 2 & 1.3 & $0.9-2.0$ & 0.71 \\
\hline Nonsquamous & 102 & 10 & & & \\
\hline
\end{tabular}

CI, Confidence interval. Nonsquamous includes adenocarcinoma and large-cell carcinoma.

was conducted by the North American Lung Cancer Study Group and reported by Ginsberg and Rubinstein. ${ }^{1}$ They noted a higher local/regional recurrence rate and death rate in the segmentectomy group as compared with the lobectomy group. According to their report, the importance of accurate intraoperative staging including lymph node sampling is demonstrated by the evidence that more than $25 \%$ of patients with lung cancer deemed to be clinically $\mathrm{T} 1$ N0 were found to have a higher stage of disease after the intraoperative primary tumor and lymph node assessment.

Although this is not a randomized study, both limited resection and lobectomy have been carried out by the same surgical staffs in our institution. In our patients the hilar and mediastinal nodes were dissected, and the specimens were then submitted for frozen section analysis before a decision was made regarding the amount of lung to be removed. As a result, we could exclude two patients (3\%) in whom lymph node metastasis was detected. The two patients underwent completion lobectomy with mediastinal lymph node dissection. On the other hand, six patients had recurrence in the mediastinum after intentional or compromised limited resection. This may have resulted from insufficient mediastinal lymph node dissection. The disease in these eight patients $(12 \%)$ was considered to be at a stage higher than stage I. These findings suggest that complete mediastinal lymph node dissection is important not only for greater cure rate but also to allow more accurate pathologic staging. This procedure had been routine at our institution since 1995 . When lymph node metastasis is confirmed on intraoperative frozen section, the procedure should be altered from a limited resection to the standard lobectomy to achieve more complete hilar lymphadenectomy.

Another important goal is to prevent cancer recurrence at the resected margin. To achieve this objective, we ${ }^{4}$ developed the new technique designated "radical laser segmentectomy" combined with nonanatomic segmentectomy using the $\mathrm{Nd}$ :YAG laser and lymph node dissection at the pulmonary hilum and mediastinum. With this technique, we believe that small peripheral tumors located in any segments of the upper lobe, or superior or anterior basal segments of the lower lobe, become good candidates for limited resection. On the other hand, for middle lobe and medial, lateral, and posterior basal segments of the lower lobe, because of the necessity for maintaining a safe margin at least $3 \mathrm{~cm}$ wide, insufficient residual volume and function in the affected lobe may be present after the procedure. Thus the candidates for limited resection should be selected only after careful consideration of tumor size, location, and shape.

In the present study, multivariate analysis demonstrated that tumor size provides prognostic information. Recently, as a result of the development of high-resolution computed tomographic scanning, small lung cancers less than $1 \mathrm{~cm}$ in diameter are being detected more frequently. Patients with these tumors are good candidates for a limited resection. 
Although a long-term detailed follow-up is necessary, the data from our series suggest that, in selected patients, a segmentectomy or bisubsegmentectomy combined with regional lymph node dissection including the mediastinum is an acceptable option for the management of T1 N0 NSCLC.

\section{REFERENCES}

1. Ginsberg RT, Rubinstein LV (Lung-Cancer Study Group). Randomized trial of lobectomy versus limited resection for T1N0 non-small cell lung cancer. Ann Thorac Surg 1995;60:615-23.

2. Read RC, Yoder G, Schaeffer RC. Survival after conservative resection for T1N0M0 non-small cell lung cancer. Ann Thorac Surg 1990;49:391-400.
3. Jensik RJ, Faber LP, Kittle CF, Meng RL. Survival following resection for a second primary bronchogenic carcinoma. J Thorac Cardiovasc Surg 1981;82:658-68.

4. Kodama K, Doi O, Yasuda T, Higashiyama M, Yokouchi H. Radical laser segmentectomy for T1NO lung cancer. Ann Thorac Surg 1992;54:1193-5.

5. Jensik RJ, Faber LP, Milloy FJ, Monson DO. Segmental resection for lung cancer: a fifteen-year experience. J Thorac Cardiovasc Surg 1973;66:563-72.

6. Stair JM, Womble J, Schaefer RF, Read RC. Segmental pulmonary resection for cancer. Am J Surg 1985;150:65964.

7. Warren WH, Faber LP. Segmentectomy versus lobectomy in patients with stage I pulmonary carcinoma. J Thorac Cardiovasc Surg 1994;107:1087-94.

\section{Availability of Journal back issues}

As a service to our subscribers, copies of back issues of The Journal of Thoracic and Cardiovascular Surgery for the preceding 5 years are maintained and are available for purchase from Mosby at a cost of $\$ 15.00$ per issue until inventory is depleted. The following quantity discounts are available: $25 \%$ off on quantities of 12 to 23 , and one third off on quantities of 24 or more. Please write to Mosby-Year Book, Inc., Subscription Services, 11830 Westline Industrial Drive, St. Louis MO 63146-3318, or call 800-453-4351 or 314-453-4351 for information on availability of particular issues. If unavailable from the publisher, photocopies of complete issues may be purchased from UMI, 300 N. Zeeb Rd., Ann Arbor, MI 48106, 313-761-4700. 